International Journal of Engineering \& Technology, $7(2.5)(2018) 84-87$
International Journal of Engineering \& Technology
SPC
Website: www.sciencepubco.com/index.php/IJET
Research Paper

\title{
Bearing Capacity of Floating Foundations Used PVC (Poly Vinyl Chloride) on Soft Soil With The Scale Model in the Field
}

\author{
Susy Srihandayani ${ }^{1}$, Desi Putri ${ }^{2}$, Nuning Kurniasih ${ }^{3}$, Lusi Dwi Putri ${ }^{4 *}$ \\ ${ }^{1}$ Sekolah Tinggi Teknologi Dumai \\ ${ }^{2}$ Sekolah Tinggi Teknik PLN \\ ${ }^{3}$ Universitas Padjadjaran \\ ${ }^{4 *}$ Universitas Lancang Kuning \\ *Corresponding author E-mail: lusidwiputri@unilak.ac.id
}

\begin{abstract}
A soft clay soil has a low support energy, so it needs to be planned a foundation form that able to improve soil bearing capacity and estimate a maximum load that can be supported by that soil. Planning a float foundation is one of the solutions to overcome that problem. The behavior of burden degradation at float foundation which obtained from encumbering of axial introduced here. Proposed analysis based on classical theory and examination of foundation at the field. Float foundation models with different amount and dimension. At the field, a pipe which one of its ends closed tightly came into soft clay soil and then encumbered step by step. Giving an axial burden and degradation model area and noted. Boundary capacities in each foundation model estimated from the curve of load-displacement yielded of the test. From the result of theoretical analysis at a single float foundation got a proportionate result with the field result but after giving additional pile/pipe with larger one's cap got the theoretical result of bearing capacity bigger than the field result. The efficiency value of the comparison of bearing capacities theoretically that using five classic methods got more than $100 \%$, and after giving additional pipe, the efficiency value near to $100 \%$.
\end{abstract}

Keywords: bearing capacity, efficiency, floating foundation, PVC pipe

\section{Introduction}

In line with the development of the Indonesian nation, the need for land for the development continues to increase[1], [2], including to create settlements that are habitable and sustainable [3], so that the new development must be done on the land which is less qualified; such as on the soft soil and on the ground which is less stable when there is a vibration or the earthquake[1]. The soil should be able to support and sustain the load from the construction which is placed on it without any shear collapse and the excessive decline. The shear collapse occurs when the carrying of the soil is exceeded. The excessive decline will cause the structural damage to the skeleton, the disturbance such as doors and windows which are difficult to open, the cracks in the porcelain and plastering, and the damage to the equipment due to misalignment of the foundation.

\section{Literature Review}

The soil type affects the magnitude of the stress zone which occurs due to the loading [4], [5]. This happens because each type of the soil has many different strengths in holding the load. For the subsurface conditions which have many different layers of soil, the dispersal of loading will be different from the unsound ground condition.

The soft soil clay is one of the problems in planning the foundation of a structure because it has a weak carrying capacity [6], [7]. In the face of this soil, the condition needs to be planning a form of foundation which can increase the carrying capacity of the soil and the estimated maximum load that can be borne by the soil. The planning of the foundation of a construction is strongly influenced by the carrying capacity of the land where the construction is established. The carrying capacity of the soil should be capable of picking up the load to keep it stable. In planning the foundation of the large load building on the ground with has a low carrying capacity, it can be used the raft foundation [8] which is the foundation of a square foot made on the soft soil and seem to float like a raft. In general, the raft foundation can be supported by piles, forming a raft-pile foundation on the soft soil [9]. Therefore, the author is interested in carrying out the load testing on a raft foundation with a $20 \mathrm{~cm}$ PVC (Poly Vinyl Chloride) pipe as a pile replacement support material with a scale model in the field and 
calculating the carrying capacity which can be borne by the foundation (floating foundation).

\section{Methodology}

\subsection{Preparatory work}

\subsubsection{The selection of the soil layers in the field}

The soil layer is selected with soft clay soil conditions and is estimated to be almost $100 \%$ passing the filter number 200. Prior to field testing, sampling (boring and sampling) ASTM D 1452-65 is undisturbed.

\subsubsection{The laboratory test result of soil}

Soil parameters: Water content ( w ) ASTM D 2216-71

a. Unit volume $(\gamma)$ ASTM D $2937-83$

b. Specific gravity ( Gs ) ASTM D $854-58$

Atterberg limit ASTM D 2216-80

a. Liquid limit

b. Plastic limit

Grained size analysis ASTM D 2487 - 69

a. Sieve analysis

b. Hydrometer analysis

Unconfined compressive strength test ASTM D 2166-66

a. Consolidate test ASTM D 2435 - 70

b. Triaxial test ASTM D 2850-70

\subsubsection{Manufacture of the test object}

The test specimen consists of a raft foundation. For a test object using a used plastic drum size $\phi 60-90 \mathrm{~cm}$ as a support material for the raft foundation o the soft clay soil for full- scale field testing conditions.

\subsection{The implementation of loading on the foundation model}

In this test, the method used is a constant Speed Penetration method which often shortened with CRP (Constant Rate Penetration)[10]. The test is performed by testing the pole under the load which is applied continuously by a hydraulic jack with the speed of penetration of the ground constant. At the time of the test, the compression force required for the continuous penetration of the pile was recorded. The reduction of the pole head is measured using a measuring monitor supported by a fixed beam. The detailed testing steps are as follows:

a. The test specimen is placed on the ground with a certain depth.

b. On the test, the specimen is given a dial to read the drop of the specimen due to the loading

c. Assign loads to test the specimens of varying magnitude from a small to a large. The load is provided with a hydraulic jack.

d. Observe and note the decrease due to the load by reading the dial down

e. The processes from an until $\mathrm{d}$ are performed for the five foundation models.

From the test result in the field, it is obtained the relation graphs between the load with the decrease to get the ultimate power support and the relation graph with the time.

\subsection{Flowchart of the research}

The method of the research is the procedure of conducting the research in order to find a solution to the research problem that will be done. The path can be seen from the following flow chart in figure 1 .

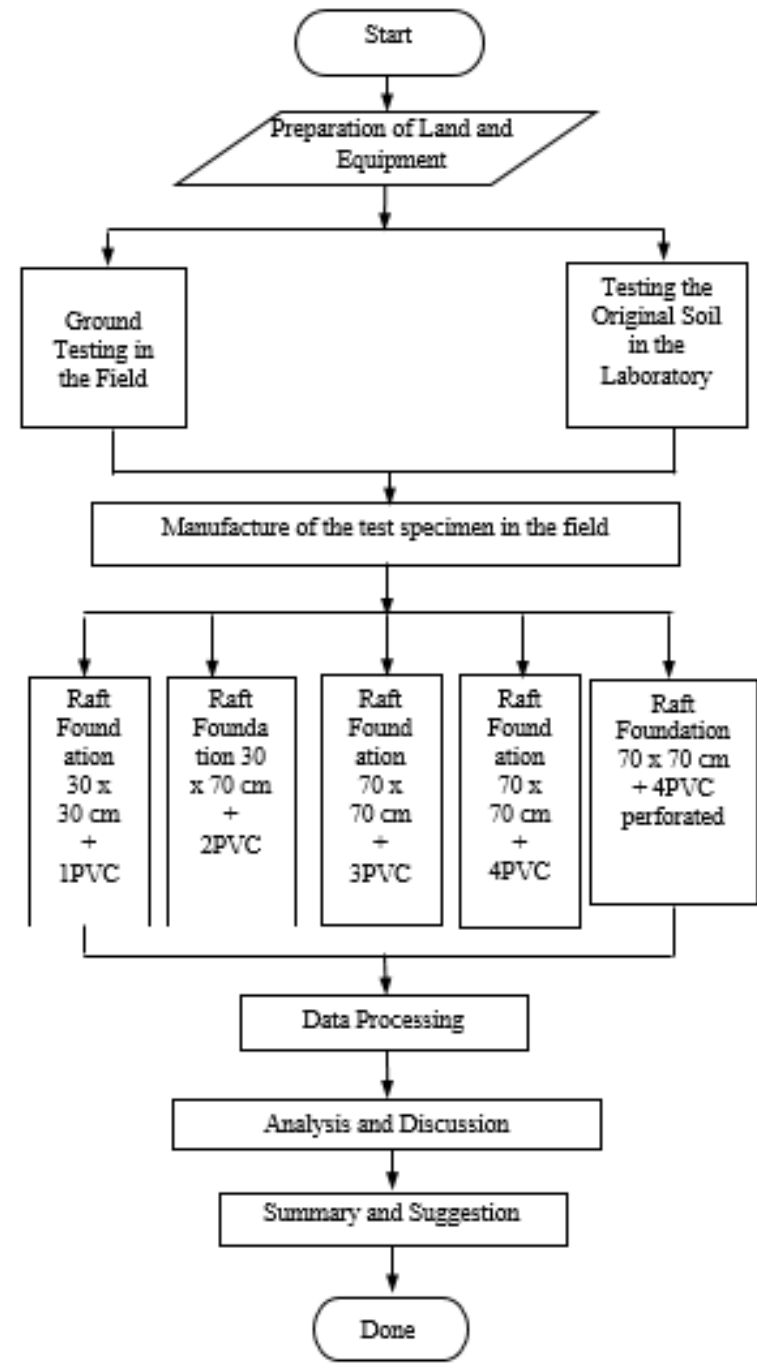

Fig.1: Flowchart Experiment

\section{Results and Discussion}

\subsection{Soil parameter testing result}

The following is a recapitulation of the result of the land parameter testing of the Aie Paducah area of Padang City in table 1.

Table.1: The Result of the Soil Parameter Test

\begin{tabular}{|c|c|c|c|c|}
\hline No & Type of Testing & Parameter & Value & Unit \\
\hline 1 & Water Content & $\mathrm{w}$ & 58,642 & $\%$ \\
\hline 2 & Volume Weight & $\gamma$ & 1,648 & $\mathrm{gr} / \mathrm{cm}^{3}$ \\
\hline 3 & Specific gravity & Gs & 2,592 & - \\
\hline \multirow{3}{*}{4} & \multirow{3}{*}{ Atterberg Limits } & $\mathrm{LL}$ & 59,372 & $\%$ \\
\hline & & PL & 40,347 & $\%$ \\
\hline & & PI & 19,025 & $\%$ \\
\hline \multirow{2}{*}{5} & \multirow{2}{*}{ Direct Shear } & $\phi$ & 7,990 & o \\
\hline & & $\mathrm{c}$ & 0,098 & $\mathrm{~kg} / \mathrm{cm}^{2}$ \\
\hline 6 & UCST & $\mathrm{q}_{\mathrm{u}}$ & 0,258 & $\mathrm{~kg} / \mathrm{cm}^{2}$ \\
\hline 7 & Granular Analysis & $\%<$ silt & 74,384 & $\%$ \\
\hline \multirow{2}{*}{8} & \multirow{2}{*}{ Consolidation } & $\mathrm{C}_{\mathrm{v}}$ & 0,034 & $\mathrm{~cm}^{2} / \mathrm{dtk}$ \\
\hline & & $\mathrm{P}_{\mathrm{c}}$ & 0,130 & $\mathrm{~kg} / \mathrm{cm}^{2}$ \\
\hline \multirow{2}{*}{9} & \multirow{2}{*}{ Tri-Axial } & $\phi_{\mathrm{u}}$ & 0,00 & o \\
\hline & & $\mathrm{c}_{\mathrm{u}}$ & 0,08 & $\mathrm{~kg} / \mathrm{cm}^{2}$ \\
\hline
\end{tabular}

\subsection{Theoretical of bearing capacity analysis}

Based on the soil data obtained from the laboratory (Table 1), the calculation of carrying capacity of the floating foundation limits theoretically using some classic formulas such as Mayerhof, Janbu, 
Skempton, Vesic and Terzaghi methods for each type of Foundation model. To determine the friction/ side support $\left(\mathrm{Q}_{\mathrm{s}}\right)$ uses the Alpha method $(\alpha)$.

\subsection{The analysis of bearing capacity of the load test in the field}

A series of test models for the next pole - pipe PVC/ raft pipe test system was carried out by adopting a modified CRP procedure [10]. This modified CRP procedure is to provide the load to the foundation with a fixed which increase of one minute in such way. From the testing of circuit model pile/ pipe raft filed consists of five types of foundation models. The distance between the poles is made twice the diameter of PVC pipe used. The test results are presented in the form of load - settlement curve and settlement time curve in Fig 2-4 [11]. From the load - decrease curve we get the ultimate carrying capacity using Mazurkiewicz and Chin. From the results of the analysis of the data which obtained from the testing field, Mazurkiewicz method and Chin method can be used and suitable for this type of floating foundation, because it depends on the material used.

\subsection{Resume of ultimate bearing capacity results calculation}

Resume of ultimate carrying capacity results calculation can be seen from the following table in table 2 and table 3.

Table.2: Resume of the ultimate bearing capacity of the theoretical result

\begin{tabular}{|l|l|l|l|l|l|}
\hline \multirow{2}{*}{$\begin{array}{l}\text { Founda } \\
\text { tion } \\
\text { model }\end{array}$} & \multicolumn{4}{|c|}{ The ultimate bearing capacity of the theoretical result (kg) } \\
\cline { 2 - 6 } & Mayerhof & Janbu & Skempton & Vesic & Terzaghi \\
\hline M. I & 231,837 & 240,517 & 252,956 & 221,234 & 243,004 \\
\hline M. II & 684,9 & 728,083 & 772,76 & 663,702 & 731,336 \\
\hline M. III & 966,903 & 1024,622 & 1086,228 & 935,106 & 1029,972 \\
\hline M. IV & 1087,716 & 1141,155 & 1205,265 & 1045,320 & 1149,856 \\
\hline M. V & 1053,65 & 1107,089 & 1171,198 & 1011,252 & 1115,788 \\
\hline
\end{tabular}

In table 2 show the theoretical analysis results obtained the ultimate capacity in the foundation model I ( 1 pipe + cap size $30 \mathrm{~cm} x$ $30 \mathrm{~cm}$ ) is smaller than the carrying capacity of the test result in the field, but the difference is not too large.

Table.3: Resume of the ultimate bearing capacity of the field result

\begin{tabular}{|l|c|c|}
\hline \multirow{2}{*}{$\begin{array}{l}\text { Foundation } \\
\text { model }\end{array}$} & \multicolumn{2}{|c|}{ The ultimate bearing capacity of the theoretical result (kg) } \\
\cline { 2 - 3 } & Mazurkiewicz Method & Chin Method \\
\hline M. I & 280 & 357,143 \\
\hline M. II & 285 & 384,615 \\
\hline M. III & 297 & 476,19 \\
\hline M. IV & 305 & 502,513 \\
\hline M. V & 263 & 333,333 \\
\hline
\end{tabular}

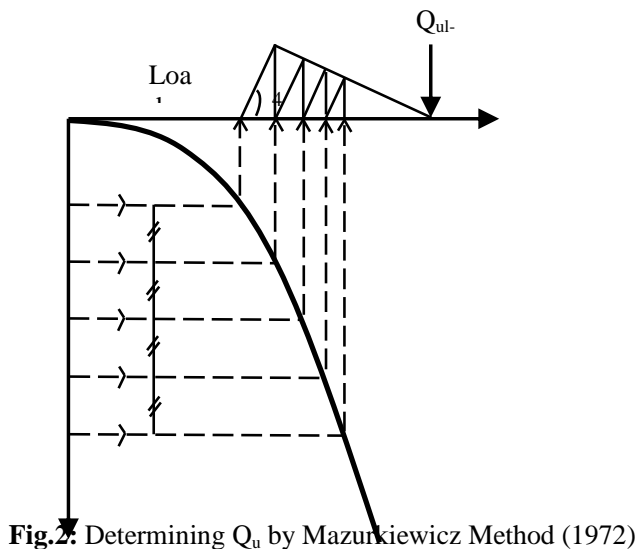

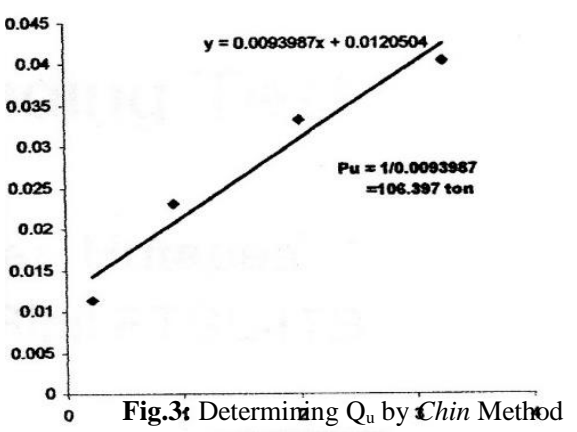

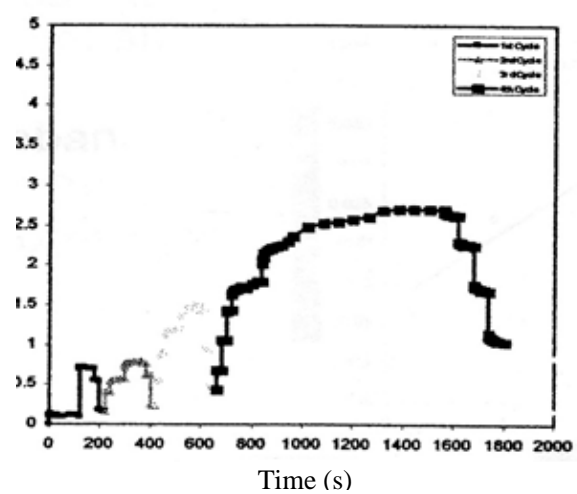

Fig.4: Decrease Graph and Time

After the addition of the pipe into the foundation of the group pole, the carrying capacity increases in accordance with the number of pipes provided, so that the ultimate capacity of the field yield capacity is three times smaller than the theoretical results. From the calculation of the carrying capacity in each model of the foundation determination of the poling efficiency on a single pole is also taken into account. In this case, the effect of the pile group efficiency is only as a preliminary clue to know the number of the poles needed at the full load of the structure. For the analysis using the equation:

Table.4: The efficiency values of the floating foundation group (calcula-

\begin{tabular}{|c|c|c|c|c|}
\hline \multicolumn{5}{|c|}{ Group Efficiency (\%) } \\
\hline \multicolumn{2}{|c|}{ Method } & I - II & I - III & I - IV \\
\hline \multirow{5}{*}{ Theory } & Mayerhoff & 147,711 & 139,021 & 117,293 \\
\hline & Janbu & 151,358 & 142,003 & 118,615 \\
\hline & Skempton & 152,746 & 143,138 & 119,118 \\
\hline & M. Terzaghi & 136,529 & 128,239 & 107,515 \\
\hline & M. Vesic & 165,309 & 155,209 & 129,961 \\
\hline \multirow{2}{*}{ Field } & Mazurkiewicz & 50,893 & 35,357 & 27,232 \\
\hline & Chin & 53,846 & 44,444 & 35,176 \\
\hline
\end{tabular}

From the foundation comparison analysis of floating single pole to the floating foundation of the group pole theoretically using five classical methods, see table 4 which obtained the group efficiency value is greater than 1 or $100 \%$. The result of calculation using Vesic method is bigger value and from the result calculation by using Terzaghi method is smaller than the five methods used in the calculation, it means we can take the efficiency value smaller than the result of calculation using the five methods reference. From the above experimental results of the efficiency value theory exceed $100 \%$ means the effect of reinforcement. In one system, the raft and pipe/pole will synergize to provide a carrying capacity that exceeds the sum of each. In its application, it is suggested the synergy impact of the raft and pipe in the raft-pile system is not to be accounted for. However, this is compensated by taking the efficiency value of $100 \%$, but from the field test result which cal- 
culated by using Mazurkiewicz and Chin method efficiency value below $100 \%$. The determination of the efficiency value as a guide in the use of the poles number which will be used to bear the load structure above it. However, from the analysis results, found that the foundation of the group piles, especially the foundation model II has a higher efficiency value compared to the foundation model which has more pole/ piles. This means the use of more pipes is less efficient for floating the foundation planning.

\subsection{The differences of foundation model IV with the foundation model $\mathrm{V}$}

Another case occurs in foundation model IV (4PVC + Cap sz. $70 \mathrm{~cm} \times 70 \mathrm{~cm}$ ) with the foundation model V (4PVC pipe whole cover + Cap sz. $70 \mathrm{~cm} \times 70 \mathrm{~cm}$ ) in fig 6 . The foundation model $\mathrm{V}$ has a raft shape and the same number of piles as the foundation model IV. But there are some differences in both of these foundation models. For example, with the addition of the same load and the same period of the time, the foundation model IV has a value of carrying capacity greater than the carrying capacity of the foundation model $\mathrm{V}$. The same thing happens when viewed from the behavior of the decline. On the foundation model V, the changes decrease over the time is larger so that the faster decline occurs when compared with the decline in foundation model IV. The breaking capacity of the carrying capacity and the magnitude of the decline in foundation $\mathrm{V}$ causes, among others, the buoyant force not to work on the foundation $\mathrm{V}$ where one end of the lid is hollowed so the air in the outlet pipe.

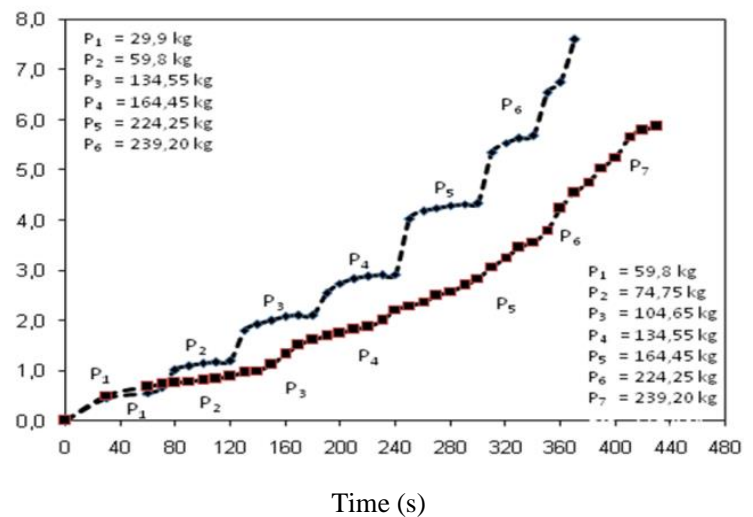

Fig. 6: The Graph of the decline of the foundation Model IVwith the foundation Model V

\section{Conclusion}

From the result of the tests which have been done in the field of each model foundation, found the following conclusion: The ultimate carrying capacity analysis using classical theory is propor- tional to the results obtained from the field data for the foundation model I (cap $30 \mathrm{~cm} \times 30 \mathrm{~cm}+1$ PVC), but after the addition of the pipe to the group's floating foundation, the carrying capacity increases, and the theoretically derived results greater than the test results in the field. Judging from the carrying capacity of the foundation model V (Cap sz. $70 \mathrm{~cm} \times 70 \mathrm{~cm}+4$ pipes PVC diameter $20 \mathrm{~cm}$ with one end of the pipe covered in hole) with the foundation model IV (Cap sz $70 \mathrm{~cm} \times 70 \mathrm{~cm}+4$ pipes PVC) the difference where the carrying capacity of the foundation model $\mathrm{V}$ is smaller than the carrying capacity of the foundation model IV, because the foundation model $\mathrm{V}$ does not have an increase in th carrying capacity of the water pressure inside the pipe, this is because the lid used on one end of the pipe is given a hole so that the air is stired out of the pipe. The efficiency value obtained from the ration of the group pile capacity to the single pole multiplied by the number of pipes from the ratio of carrying capacity theoretically using the five classical methods obtained exceed $100 \%$, and after the addition of the pipes, the efficiency value is approaching $100 \%$.

\section{References}

[1] D. Hartama, H. Mawengkang, M. Zarlis, and R. Rahim, "A Research Framework of Disaster Traffic Management to Smart City," in 2017 Second International Conference on Informatics and Computing (ICIC), 2017, pp. 1-5.

[2] D. Ayu, P. Sari, A. Sugiana, R. Y. Ramadhonah, S. Innaqa, and R. Rahim, "Kampung Pulo Environmental Planning Observed From Biophysical Aspects As Adaptation of Flood in Jakarta," Int. J. Eng. Technol., vol. 7, no. 2.3, pp. 82-87, 2018.

[3] L. D. Putri, Harsini, and S. R. Nasution, "Potential of regulation slum area in the village Meranti Pandak Pekanbaru City," Int. J. Eng. Technol., vol. 7, no. 2, 2018.

[4] J. E. Bowles, Analisis dan Desain Pondasi, Jilid 2. Jakarta: Erlangga, 1997.

[5] R. Rahim, S. Napid, A. Hasibuan, S. R. Sibuea, and Y. Yusmartato, "Effect of the Machined Surfaces of AISI 4337 Steel to Cutting Conditions on Dry Machining Lathe," J. Phys. Conf. Ser., vol. 1007, p. 012064, Apr. 2018.

[6] A. Lesmana, "Studi Perilaku dan Mekanisme Interaksi Penggabungan Prefabricated Vertical Drain dan Deep Cement Mixing untuk Perbaikan Tanah Lunak," Tek. Sipil, vol. 23, no. 3, pp 203-212, 2016

[7] C. Rahmawati, Z. Zainuddin, S. Is, and R. Rahim, "Comparison Between PCI and Box Girder in BridgesPrestressed Concrete Design," J. Phys. Conf. Ser., vol. 1007, no. 1, p. 012065, Apr. 2018.

[8] H. Darjanto, "Floating raft-pile foundations analysis using numerical simulation," Rekayasa Sipil, vol. 7, no. 2, pp. 39-46, 2011.

[9] A. Hakam, Rekayasa Pondasi. Padang: Bintang Grafika, 2008.

[10] F. T-bar and I. An, "Rate effects on penetrometer resistance in kaolin," Ge'otechnique, vol. 59, no. 1, pp. 41-52, 2009.

[11] B. Hutapea, "Static Loading Test," in Static Loading Test, Program Studi Teknik Sipil Institut Teknologi Bandung. 